\title{
Composition of statins produced by indigenous strain of Aspergillus terreus
}

\author{
T.G. Gulyamova ${ }^{1}$, S.M. Nasmetova ${ }^{1}$, D.M. Ruzieva ${ }^{1}$, J.F. Ziyavitdinov ${ }^{2}$, \\ R.S. Sattarova ${ }^{1}$, G.A. Rasulova ${ }^{1}$ \\ ${ }^{1}$ Department of Biochemistry of Physiologically Active Compounds, Institute of Microbiology of the Academy of Sciences RU, UZBEKISTAN \\ ${ }^{2}$ Department of Chemistry of Proteins and Peptides, Institute of Bioorganic Chemistry of the Academy of Sciences RU, UZBEKISTAN \\ *Corresponding Author: e-mail: regina.s.sattarova@gmail.com, Tel. +998-90-1898179, Fax +998-71-2442582
}

\begin{abstract}
Composition of statins produced by Aspergillus terreus 20 indigenous strain in submerged fermentation (SmF) has been studied. Identification of statin compounds in fungal extracts by LC-MS-MS analysis revealed 6 polyketide metabolites: lovastatin (LV) in lactone, acid and methyl ester forms, pravastatin (PV), monacolin L (ML) and simvastatin (SV). For the first time it has been revealed the ability producing simvastatin by $A$. terreus by direct fermentation.
\end{abstract}

Keywords: Aspergillus terreus, statins, composition, HPLC, LC-MS-MS analysis, mass spectra.

DOI: http://dx.doi.org/10.4314/ijest.v6i1.8

\section{Introduction}

Statins are fungal secondary metabolites which specifically inhibit HMG-CoA reductase on early rate-limiting step in cholesterol biosynthesis (Alberts et al., 1980). Statins reduce total cholesterol and low-density lipoprotein levels and therefore have been used as cholesterol-lowering drugs (Seenivasan et al., 2008; Endo, 2004). Natural statins are lovastatin, compactin and pravastatin. The most profound producers of natural statins are Aspergillus terreus, Monascus ruber and Penicillium citrinum (Barrios-Gonzales et al., 2010; Manzoni et al., 2002). Simvastatin, the second leading statin in the market, is a lovastatin's semisynthetic derivative. The difference in molecular structure between these two polyketides resides in the C-8 carbon position of the side chain where lovastatin carries a 2-methylbutyrate moiety, while simvastatin - a 2,2-dimethylbutyrate (DMB) moiety. Because DMB is not normally produced by A. terreus this fungus is considered not to be able to synthesize simvastatin (BarriosGonzales et al., 2010, Seenivasan et al., 2008). To date commercially simvastatin is being obtained by direct alkylation of lovastatin.

Recently, we reported about good lovastatin production by indigenous strains A. terreus 4 and A. terreus 20 both in SmF and solid state fermentation (SSF) (Gulyamova et al., 2013). This paper based on current study presents the data indicating the composition of statin metabolites produced by A. terreus 20 in submerged fermentation.

\section{Materials and Methods}

2.1 Microorganisms and inoculum preparation: A. terreus 20 was isolated from soils of Navoi region, Uzbekistan. Isolates were grown on Czapek-Dox agar slants at $28^{\circ} \mathrm{C}$ until complete sporulation. Conidiospores were harvested from slants with $5 \mathrm{ml}$ of sterile solution of $0,85 \% \mathrm{NaCl}, 0,2 \%$ Tween 80 and transferred into $250 \mathrm{ml}$ Erlenmeyer flasks containing $50 \mathrm{ml}$ medium (g/l): $10 \mathrm{~g}$ glucose, $10 \mathrm{~g}$ oat meal, $10 \mathrm{~g}$ corn steep liquor, $0,2 \mathrm{~g}$ polyethylene glycol, and $10 \mathrm{ml}$ trace elements $-100 \mathrm{mg}$ $\mathrm{Na}_{2} \mathrm{~B}_{4} \mathrm{O}_{7} \cdot 10 \mathrm{H}_{2} \mathrm{O}, 50 \mathrm{mg} \mathrm{MnCl} 2,50 \mathrm{mg} \mathrm{Na} \mathrm{MoO}_{4} \cdot 5 \mathrm{H}_{2} \mathrm{O}, 250 \mathrm{mg} \mathrm{CuSO} \cdot 5 \mathrm{H}_{2} \mathrm{O}$ - per liter of solution. The flask with medium was inoculated with $3 \times 10^{7}$ conidiospores, held on rotary shaker at $160 \mathrm{rpm}$ for 2 days at $28-30^{\circ} \mathrm{C}$ and then was used as inoculum (Kumar et al., 2000). 
2.2 Submerged fermentation: $10 \mathrm{ml}$ of conidiospores were inoculated in $300 \mathrm{ml}$ Erlenmeyer flasks, containing $100 \mathrm{ml}$ of following media (g/l): lactose - 20; yeast extract $-4 ; \mathrm{KH}_{2} \mathrm{PO}_{4}-1,51 ; \mathrm{NaCl}-0,4 ; \mathrm{ZnSO}_{4} \cdot 7 \mathrm{H}_{2} \mathrm{O}-1 ; \mathrm{Fe}\left(\mathrm{NO}_{3}\right) \cdot 9 \mathrm{H}_{2} \mathrm{O}-2$; biotin $0,04 \mathrm{мг}$, trace elements $-1 \mathrm{ml}, \mathrm{pH} 6,0$ (Casas et al., 2003). Fermentation was carried out at $28^{\circ} \mathrm{C}$ in flasks held on a rotary platform shaker at $160 \mathrm{rpm}$ for 24 days.

2.3 Statin extraction: Statins were extracted from biomass after centrifugation of the whole culture suspension at $6000 \mathrm{rpm}$ for 20 min. $1 \mathrm{~g}$ of mycelium was washed by $0,05 \mathrm{M} \mathrm{HCl}$ and extracted with $20 \mathrm{ml}$ of acetonitrile on rotary shaker for $60 \mathrm{~min}$ at 160 rpm. Extracts were dried with $\mathrm{Na}_{2} \mathrm{SO}_{4}$, concentrated to $2 \mathrm{ml}$ by vacuum evaporation and used for analysis.

2.4. LC-MS-MS analysis: Mass spectra of extracts were taken on Q-TOF LC-MS Agilent Technologies 6520B instrument under following conditions: ion source ESI+, positive ion electrospray method, drying gas flow rate $5 \mathrm{l} / \mathrm{min}$, drying gas temperature $300^{\circ} \mathrm{C}$, ion acceleration voltage on skimmer $35 \mathrm{~V}$, fragmentor $175 \mathrm{~V}$, MS range $150-1000 \mathrm{~m} / \mathrm{z}$, targeted MS-MS $50-1000 \mathrm{~m} / \mathrm{z}$, collision energy - 30, 40, 50, 65. Samples were injected on Zorbax SB C18 column, $3 \mu \mathrm{m}, 150 x 0,5 \mathrm{~mm}$ (Agilent Technologies 1200 ) with mobile phase: A - 0,1\% formic acid, B - acetonitrile $+0,1 \%$ formic acid. Elution on Agilent Technologies 1260 Cap Pump at $15 \mu \mathrm{l} / \mathrm{min}$ : $5 \mathrm{~min}-60 \%, 15-20 \mathrm{~min}-90 \%, 25 \mathrm{~min}-60 \%$ of mobile phase B. There were conducted 3 replications.

2.5. LC-MS-MS analysis of statins: HPLC was carried out in a reverse phase Zorbax Eclipse XDB C-18 (150x4,6 mm i.d., $5 \mu \mathrm{m})$ column. The mobile phase consisted of acetonitrile and water ( $60: 40$ by volume) containing $0,1 \%$ phosphoric acid. The sample injection volume was $20 \mu \mathrm{l}$, the eluent flow rate was $1.5 \mathrm{ml} / \mathrm{min}$ and the detection wavelength $238 \mathrm{~nm}$. Pharmaceutical-grade lovastatin (Gedeon Richter) and simvastatin (Ivex Pharmaceuticals) tablets were used to prepare the standards for HPLC analysis (Morovjan et al., 1997). There were conducted 3 replications.

\section{Results and Discussion}

In previous studies it was established that $A$. terreus 20 indigenous strain produces sufficiently high amount of lovastatin both in SmF and SSF (Gulyamova et al., 2013) but composition of statins was not studied. The presence of lovastatin in A. terreus 20 extracts was analyzed by HPLC (Figure1).

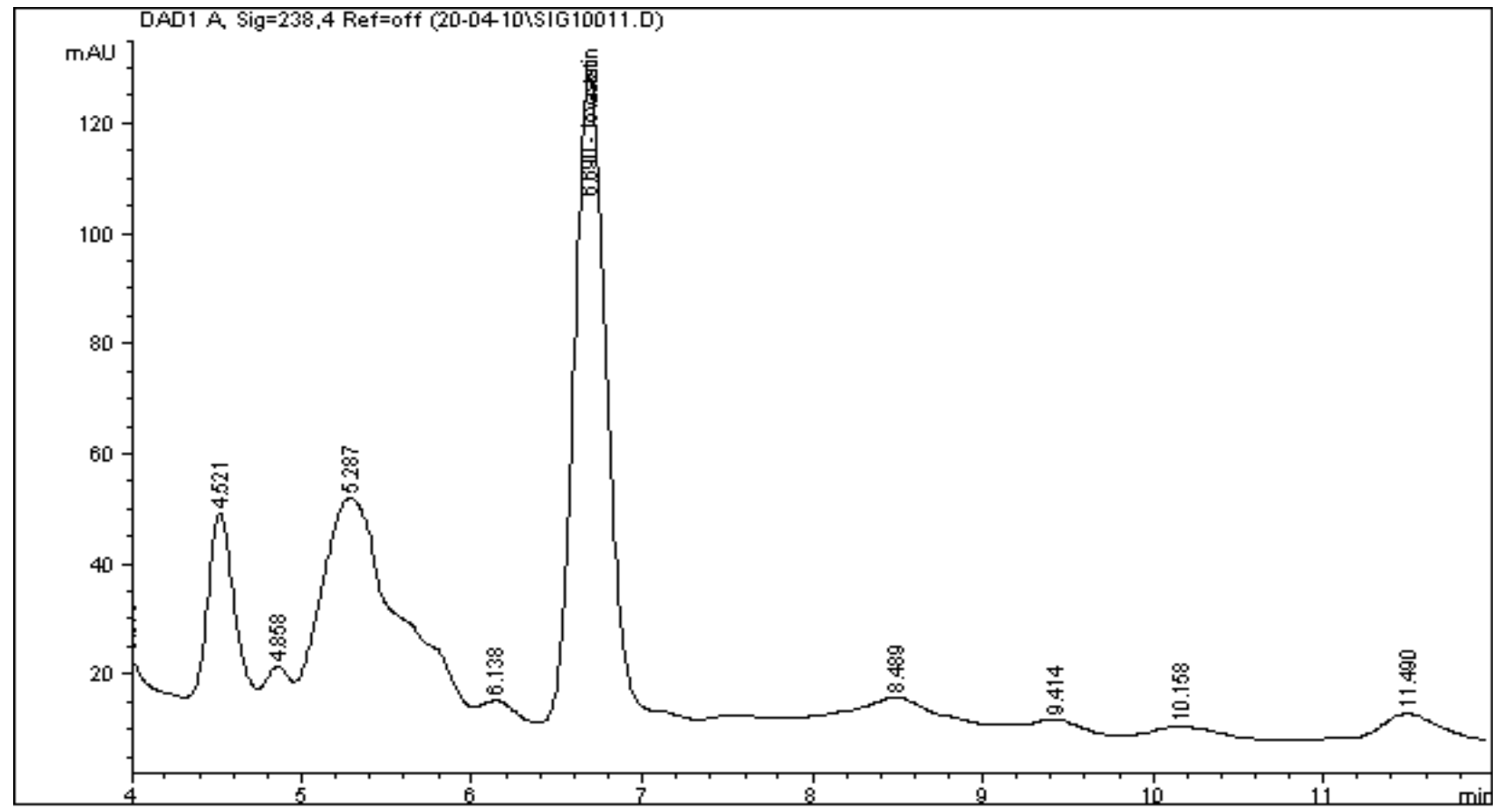

Figure 1. HPLC-chromatogram of extract of A. terreus 20

In this study, the identification of statin metabolites in A. terreus acetonitrile extracts was performed by comparing the retention times and mass spectra with those of standards in the same chromatographic conditions on Q-TOF LC-MS Agilent Technologies 6520B instrument. To avoid or limit the interference from background, the multiple reactions monitoring analysis mode was used instead of single ion monitoring (e.g., MS-MS instead of MS). TIC-chromatogram of A. terreus 20 extracts 
presented in Figure 2. As opposed to HPLC-chromatogram a number of high intensity compounds were observed in hydrophobic region of TIC- chromatogram.

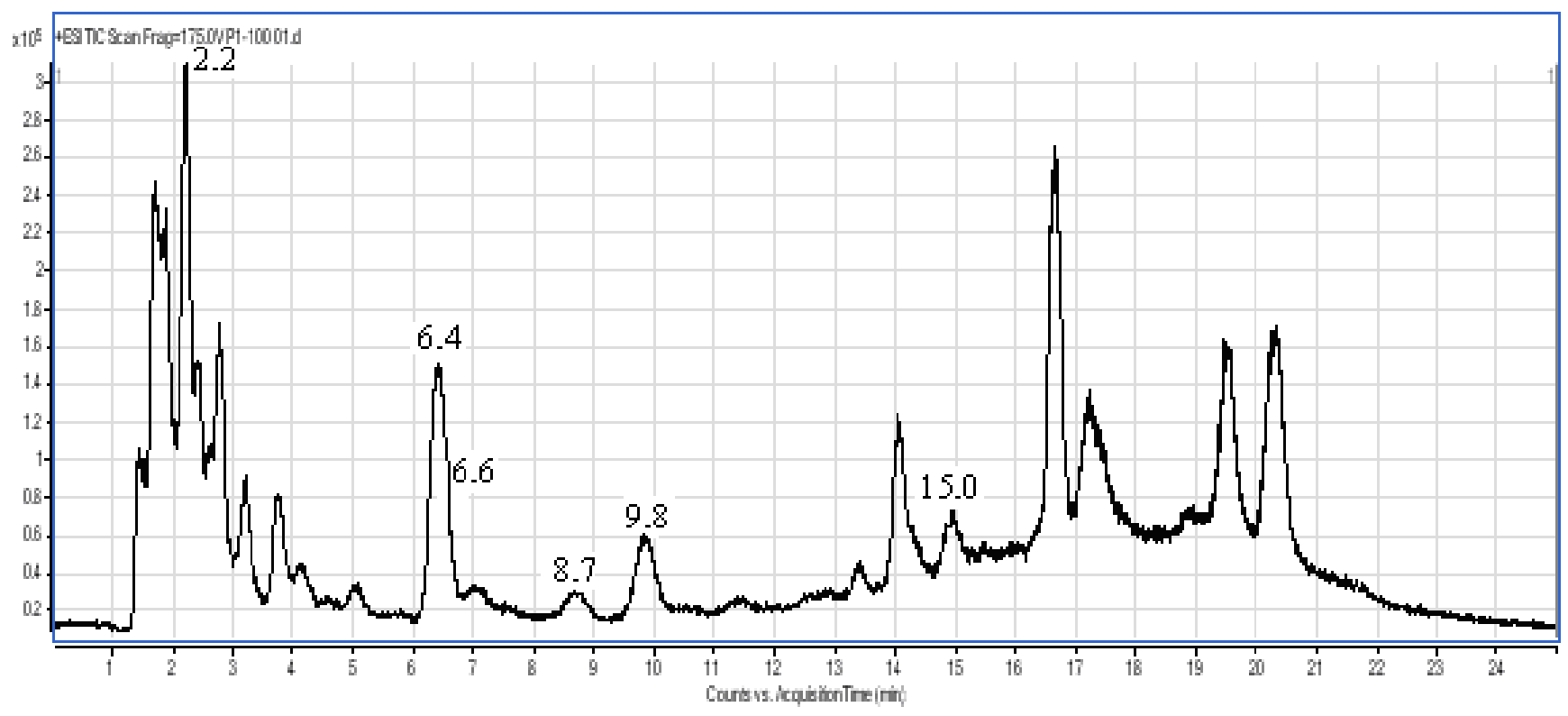

Figure 2. TIC-chromatogram of extract of A.terreus-20.

The peaks from left to right are ordered PV (2.2 min), LV (6.4 min), LA (6.6 min), SV (8.7 min), ML (9.8 min), LM (15.0 min)

For identification of each compound Targeted MS-MS was used. According to data shown in Figures 3 and 4 MS-MS spectra of acetonitrile extracts of A.terreus 20 indicates the presence of compounds with molecular mass of lovastatin and simvastatin $\left((\mathrm{M}+\mathrm{H})^{+} 405,2205 \mathrm{~m} / \mathrm{z}\right.$ and $(\mathrm{M}+\mathrm{H})^{+} 419,2362 \mathrm{~m} / \mathrm{z}$, respectively) as lactones.

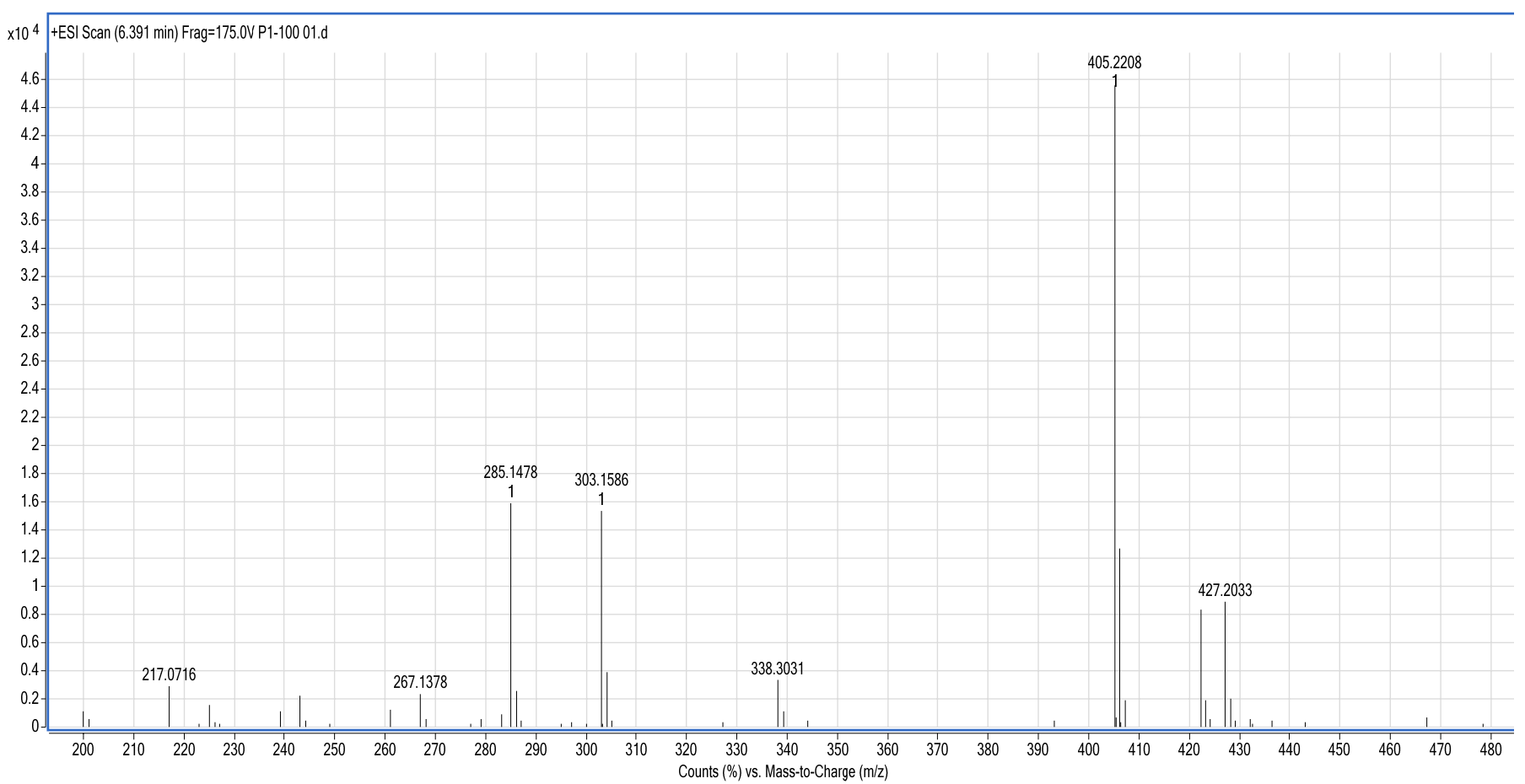

Figure 3. MS spectra of lovastatin $(\mathrm{M}+\mathrm{H})^{+} 405,2205 \mathrm{~m} / \mathrm{z}$ 


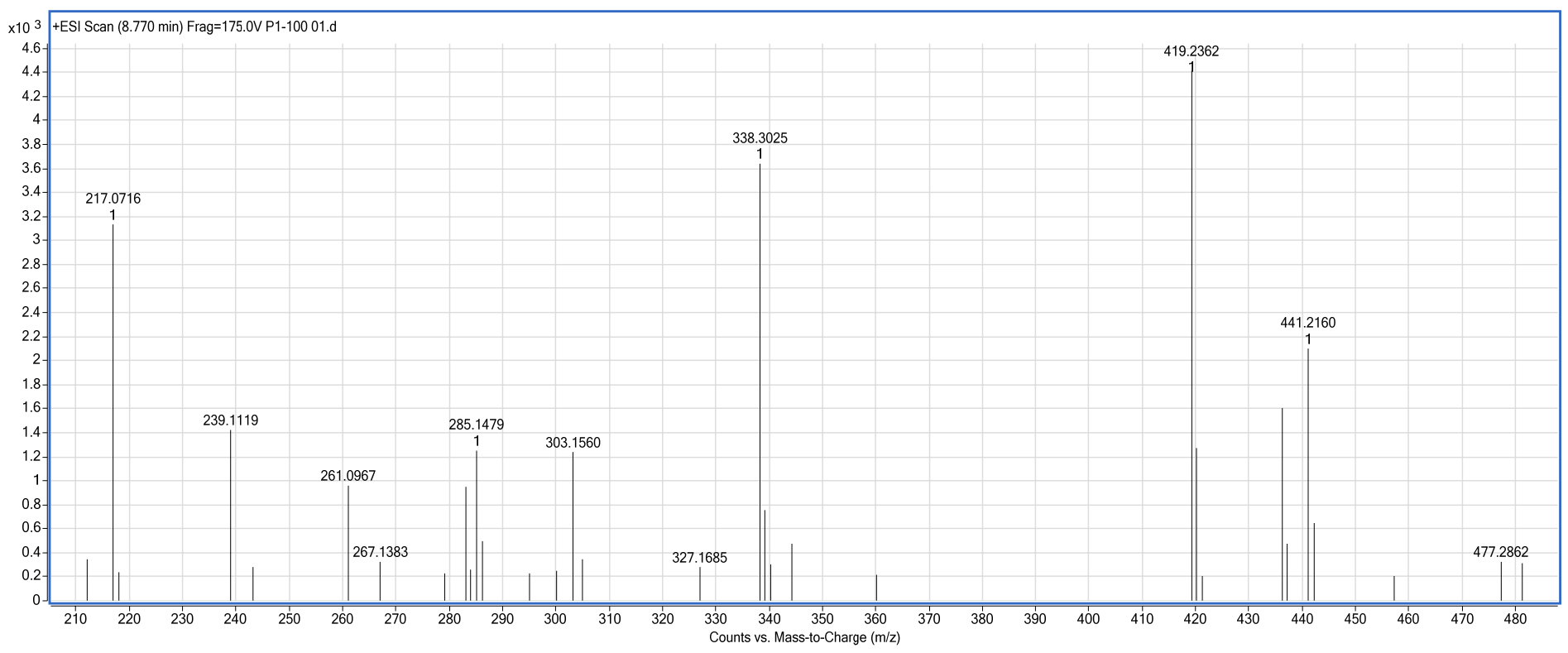

Figure 4. MS spectra of simvastatin $(\mathrm{M}+\mathrm{H})^{+} 419,2362 \mathrm{~m} / \mathrm{z}$

Experimental results reveal that lovastatin was presented in three different forms: as lovastatin lactone $(\mathrm{M}+\mathrm{H})^{+} 405,2205 \mathrm{~m} / \mathrm{z}$, lovastatin hydroxyacid $\left((\mathrm{M}+\mathrm{H})^{+} 422,2469 \mathrm{~m} / \mathrm{z}\right)$ and lovastatin methyl ester $\left((\mathrm{M}+\mathrm{H})^{+} 436.3890 \mathrm{~m} / \mathrm{z}\right)$. There are also derivatives in the samples, appropriate to pravastatin $\left((\mathrm{M}+\mathrm{H})^{+} 425,1159 \mathrm{~m} / \mathrm{z}\right)$ and monacolin $\mathrm{L}\left((\mathrm{M}+\mathrm{H})^{+} 305,1173 \mathrm{~m} / \mathrm{z}\right)($ Table 1$)$.

Table 1. MS data of statins in A. terreus 20 extracts

\begin{tabular}{|l|c|c|}
\hline Compound & Molecular ion $\left.\mathbf{( M}^{+}\right)$ & Retention time (min) \\
\hline Pravastatin (PV) & $425,1159 \mathrm{~m} / \mathrm{z}$ & 2,2 \\
\hline Lovastatin (LV) & $405,2205 \mathrm{~m} / \mathrm{z}$ & 6,4 \\
\hline Lovastatin acid (LA) & $422,2469 \mathrm{~m} / \mathrm{z}$ & 6,6 \\
\hline Simvastatin (SV) & $419,2362 \mathrm{~m} / \mathrm{z}$ & 8,7 \\
\hline Monacolin L (ML) & $305,1173 \mathrm{~m} / \mathrm{z}$ & 9,8 \\
\hline Lovastatin methyl ester (LM) & $436,3890 \mathrm{~m} / \mathrm{z}$ & 15,0 \\
\hline
\end{tabular}

Manzoni et al. reported that some A. terreus strains can produce appreciable yields of pravastatin as well as lovastatin (Manzoni et al., 1998). But determination of SV in extracts was quite unexpected because of normally A. terreus is considered not to be able to produce this derivative due lack of DMB endogenous synthesis (Barrios-Gonzales et al., 2010, Seenivasan et al., 2008). Moreover, for the last years advances in the biochemistry and genetics of lovastatin have allowed the development new biotechnological processes for obtaining of SV. One of the biotechnological approaches for its production would be the enzymatic synthesis of SV from monacolin J (MCJ) with acyltransferase LovD (Xie et al., 2007). Using combinatorial biocatalytic approach it has been engineered $A$. terreus strain with hybrid polyketide synthase enable to synthesize DMB in vivo as side chain of SV. Transformed strain of A. terreus can produce SV instead of LV by direct fermentation (Van den Berg et al., 2007). Hereby, as opposed to previous studies of Aspergillus strains indigenous A. terreus 20 obviously is able to synthesize DMB promoting SV production as final product of fermentation. 


\section{Conclusions}

Our results demonstrate that composition of statins producing by A. terreus 20 includes 6 polyketide metabolites: LV in lactone, acid and methyl ester forms, PV, ML and SV. Obtained data indicates the existence in A. terreus 20 biochemical mechanism for biotransformation which allowed formation and accumulation of SV in the culture as a final fermentation product. Although the particular pathway of SV production has not been studied yet, detection of this statin presumes ability of A. terreus 20 to synthesize DMB as side chain precursor. On the basis of obtained data we conclude that indigenous strain A. terreus 20 could be an alternative to the biotransformation process cited in the literature (Barrios-Gonzales et al., 2010).

\section{References}

Alberts A.W., Chen J., Kuron G., Hunt V., Huff J., Hoffman C., Rothrock J., Lopez M., Joshua H., Harris E., Patchett A., Monaghan R., Currie S., Stapley E., Albers-Schonberg G., Hensens O., Hirshfield J., Hoogsteen K., Liesch J., Springer J. 1980. Mevinolin: a highly potent competitive inhibitor of hydroxymethylglutaryl-coenzyme A reductase and a cholesterollowering agent. Proceedings of the National Academy of Sciences of the United States of America, Vol. 77, pp. 3957-3961.

Seenivasan A., Subhagar S., Aravindan R., Viruthagiri T. 2008. Microbial production and biomedical applications of lovastatin. Indian Journal of Pharmaceutical Sciences, Vol. 70, pp. 701-709.

Endo A. 2004. The origin of statins. International Congress Series, Vol. 1262, pp. 3-8.

Barrios-Gonzales J., Miranda R.U. 2010. Biotechnological production and applications of statins. Applied Microbiology and Biotechnology, Vol. 85, pp. 869-883.

Manzoni M., Rollini M. 2002. Biosynthesis and biotechnological production of statins by filamentous fungi and application of these cholesterol-lowering drugs. Applied Microbiology and Biotechnology, Vol. 58, pp. 555-564.

Gulyamova T.G., Ruzieva D.M., Nasmetova S.M., Sattarova R.S., Lobanova K.V., Abdulmyanova L.A, Rasulova G.A. 2013. Lovastatin production by Aspergillus terreus in solid state and submerged fermentations. International Journal of Engineering, Science and Technology, Vol. 5, No 3, pp. 19-24.

Kumar M.S., Jana S.K., Senthil V., Shashanka S., Kumar S.V., Sadhukhan A.K. 2000. Repeated fed batch process for improving lovastatin production. Process Biochemistry, Vol. 36, pp. 363-368.

Casas Lopez J.L., Sanchez Perez J.A., Fernandez Sevilla J.M., Acien Fernandez F.G. et al. 2003. Production of lovastatin by Aspergillus terreus: effects of the $\mathrm{C}: \mathrm{N}$ ratio and the principal nutrients on growth and metabolite production. Enzyme and Microbial Technology, Vol. 33, pp. 270-277.

Manzoni M., Rollini M., Bergomi S., Cavazzoni V. 1998. Production and purification of statins from Aspergillus terreus strains. Biotechnology Techniques, Vol.12, No. 7, pp. 529-532.

Morovjan G., Szakacs G. and Fekete J. 1997. Monitoring of selected metabolites and biotransformation products from fermentation broths by high-performance liquid chromatography. Journal of Chromatography. A, 763, pp. 165-172.

Xie X., Tang Y. 2007. Efficient synthesis of simvastatin using whole-cell biocatalysis. Applied and Environmental Microbiology, Vol. 73, pp. 2054-2060.

Van den Berg M.A, Hans M., Streekstra H. 2007. Method for the production of simvastatin. International Patent WO $2007147801 A 1$.

\section{Biographical notes}

T.G. Gulyamova is a Professor in the Department of Biochemistry and Biotechnology of Physiologically Active Compounds, Institute of Microbiology, Uzbekistan. She has more than 30 years of experience in research. Her research interests include biodiversity and biochemistry of biotechnologically important fungi, including endophytes from medicinal plants, regulation of microbial synthesis of physiologically active secondary metabolites. She has published more than forty papers in referred international journals. She has also presented more than one hundred research articles in national and international conferences and participated in collaborative projects supported by USA.. She is currently dealing with few projects sponsored by government of Uzbekistan.

S.M. Nasmetova received Ph.D. from the Institute of Microbiology, Uzbekistan Academy of Sciences in 2008. She is Senior Research Fellow in the Department of Biochemistry and Biotechnology of Physiologically Active Compounds, Institute of Microbiology, Uzbekistan. Her current area of research includes regulation of biosynthesis of statins by fungi, submerged and solid state fermentation processes, optimization technology. She is dealing with two projects sponsored by government of Uzbekistan.

D.M. Ruzieva received Ph.D. from the Institute of Microbiology, Uzbekistan Academy of Sciences in 1993. She is Senior Research Fellow in the Department of Biochemistry and Biotechnology of Physiologically Active Compounds, Institute of Microbiology, Uzbekistan. Her current area of research includes biosynthesis of secondary metabolites in fungi. She has presented about fifty research articles in national and international conferences. She participated in collaborative projects supported by USA. Currently she is dealing with two projects sponsored by government of Uzbekistan.

J.F. Ziyavitdinov received Ph.D degree from the Institute of Bioorganic Chemistry, Uzbekistan Academy of Sciences in 2002. He is Senior Research Fellow in the Department of Chemistry of Proteins and Peptides, Institute of Bioorganic Chemistry, Uzbekistan. He has more than 20 years of experience in the field of proteins and peptides investigation. His current research area includes proteomics and metabolomics. He is currently dealing with two research projects sponsored by government of Uzbekistan. 
R.S. Sattarova received Ph.D. from the Institute of Microbiology, Uzbekistan Academy of Sciences in 1993. She is Senior Research Fellow in the Department of Biochemistry and Biotechnology of Physiologically Active Compounds, Institute of Microbiology. She has received various fellowships and awards of International Organizations like DAAD, Germany; ITCILO, Italy; Royal Society, UK ; etc. Her research area includes search and study of bioactive metabolites of microorganisms with medicinal and agricultural potential. She coordinated over 20 donor funded R\&D projects supported by USA and EU in the framework of program 'Science and Technology Center in Ukraine'. She is currently dealing with few projects sponsored by governments of Uzbekistan and Korea.

G.A.Rasulova is Technical Assistant in the Department of Biochemistry and Biotechnology of Physiologically Active Compounds, Institute of Microbiology, Uzbekistan. She is dealing with two projects sponsored by government of Uzbekistan.

Received September 2013

Accepted November 2013

Final acceptance in revised form November 2013 